\title{
Study of Composites Produced with Recovered Polypropylene and Piassava Fiber
}

\author{
Stephanie Gonçalves Nunes ${ }^{a, b} *$, Laís Vasconcelos da Silva ${ }^{b}$, Sandro Campos Amico ${ }^{b}$, Josiane Dantas
}

Viana $^{c}$, Franco Dani Rico Amado ${ }^{a}$

\author{
${ }^{a}$ State University of Santa Cruz - UESC, Campus Soane Nazaré de Andrade, Rodovia Jorge Amado, \\ Km 16, 45662-900, Ilhéus, BA, Brazil \\ ${ }^{b}$ Federal University of Rio Grande do Sul-UFRGS, Av. Bento Gonçalves, 9500, 91501-970, Porto \\ Alegre, RS, Brazil \\ ${ }^{c}$ Materials Department, SENAI CIMATEC, Av. Orlando Gomes, 1845, 41650-010, Salvador, BA, Brazil
}

Received: September 12, 2016; Accepted: November 21, 2016

\begin{abstract}
This work addresses the use of piassava fibers $(\mathrm{PF})$ as reinforcement for recovered polypropylene $(\mathrm{PPr})$ in the manufacturing of composites. The composites were molded with variable amounts of PF (10, 20 and $30 \mathrm{wt} \%$ ), with and without maleic anhydride functionalized polypropylene (MAPP) (10 wt $\%$ ) as compatibilizer. The composites were characterized using mechanical tests (flexural, tensile, impact and hardness), thermal analyses (thermogravimetric analysis and differential scanning calorimetry), along with evaluations of heat deflection temperature, melting flow index, density and morphology. Tensile and flexural strength of composites increased with PF content, but impact strength decreased, since the material became stiffer. The use of MAPP in the formulations yielded superior properties, showing good fiber/matrix interaction. In all, the use of PF as reinforcement in PPr was considered an interesting way of reducing solid waste and to reinforce plastics, being a possible alternative for the substitution of wood in WPC composites.
\end{abstract}

Keywords: Composites, Piassava fiber, Recycled polypropylene, Maleic anhydride, Sustainability

\section{Introduction}

With the growth of the consumer market, the amount of solid waste has steadily increased worldwide. This is even more worrying considering the low degradability of some synthetic materials, with potential harm to humans and the environment. This has lead to the advent of the Green Building concept, whose aim is to design products with reduced impact on the environment by using renewable resources. A used material is no longer considered waste if it is later employed as raw material, and this is a great business opportunity for companies since it enables production at lower cost, with less energy and by using materials that would be otherwise discarded.

Because of their widely acceptance/use and low degradability, polymeric materials are sometimes considered an environmental problem. Polypropylene (PP), for instance, is among the most used polymers, being employed in numerous applications and comprising a significant part of the discarded polymer waste.

Researchers and industries seek more eco-friendly alternative materials capable of matching or surpassing the performance of pure polymers and this sometimes translate into the use of natural fibers, i.e. producing polymer composites. Particularly in Brazil, the availability of natural fibers is enormous and the demand for solutions related to their final disposal already exists. Brazil has favorable climate and abundant growth area with great production and market for various types of vegetable fibers and also for the waste generated by the agro-business which is an important source of vegetable fiber residues. The Bahia (BA) state, in the Northeast Region of Brazil, has the largest production of natural fibers, mainly coconut, piassava and sisal. These fibers have been investigated as reinforcement of thermoplastics because of their characteristics like low density, low cost, biodegradability, non-toxicity and renewability ${ }^{1-4}$.

For the manufacturing of natural fiber polymeric composites, it is common to use a third component to tackle fiber/matrix compatibility, which is one of the main barriers for the effective use in these composites. These coupling agents may reduce interfacial tension and improve adhesion between the phases, influencing the final properties of the composite ${ }^{5-8}$. The most commonly used coupling agent for PP composites is maleic anhydride functionalized polypropylene (MAPP), which possesses polar and nonpolar structures that may increase chemical interaction between PP and natural fibers in general $^{9}$. Therefore, the main objective of this work is to investigate the effect of MAPP in the compatibilization of recovered polypropylene with piassava fiber for the future development of elements for the construction and architecture sectors. 


\section{Experimental}

The recovered polypropylene (PPr) used in this work was derived from waste collected near the university where this work was carried out, being mostly energy drinks, margarine pots, bottles and mineral water bottle caps. The PF was provided by an organization of farmers of Nilo Peçanha (from the Bahia State of Brazil) as a mixture of unprocessed piassava and by-product of the commercial production of brooms. A chemically functionalized PP with a high content of maleic anhydride (Orevac CA100, Arkema) was used.

The PPr was milled and classified using a 16-mesh sieve. PF was also milled and subsequently classified using a set of sieves for 5 min reaching an average particle size distribution of $1.47 \pm 0.58 \mathrm{~mm}$. Afterwards, PF was dried in an air circulating oven at $110^{\circ} \mathrm{C}$ for $4 \mathrm{~h}$ for the removal of moisture and volatiles.

Five compositions were studied, as described in Table 1. The selected materials were manually mixed and processed in an IMACON twin screw co-rotating extruder model DRC 30:40 IF, with a screw diameter of $30 \mathrm{~mm}$, speed of $200 \mathrm{rpm}$, $\mathrm{L} / \mathrm{D}$ ratio of 40 and temperature zones within $160-190^{\circ} \mathrm{C}$, an usual range for the processing of PP with natural fibers ${ }^{10}$. After extrusion, the pellets were dried in an oven with air circulation at a temperature of $110^{\circ} \mathrm{C}$ for $8 \mathrm{~h}$ to remove any moisture sorbed after processing. The pellets were later processed in a ROMI 100T, 100R Model Promax plastic injection machine (temperature zones within $175-185{ }^{\circ} \mathrm{C}$ ) to obtain specimens for testing.

Table 1: Sample Nomenclature.

\begin{tabular}{lccc}
\hline Code & $\operatorname{PPr}(\mathrm{wt} \%)$ & MAPP $(\mathrm{wt} \%)$ & $\mathrm{PF}(\mathrm{wt} \%)$ \\
\hline $100 / 0 / 0$ & 100 & 0 & 0 \\
$80 / 10 / 10$ & 80 & 10 & 10 \\
$70 / 10 / 20$ & 70 & 10 & 20 \\
$60 / 10 / 30$ & 60 & 10 & 30 \\
$80 / 0 / 20$ & 80 & 0 & 20 \\
\hline
\end{tabular}

\subsection{Characterization}

Density measurements were performed according to ASTM D792. The heat deflection temperature (HDT) was measured according to ASTM D648 in the CEAST HDT Vicat machine with a heating rate of $120^{\circ} \mathrm{C} / \mathrm{h}$ and an applied stress of $1.82 \mathrm{MPa}$. The melt flow index (MFI) was measured in accordance with ASTM D1238, in a Modular Melt Flow Model CEAST MF30 equipment, using $190^{\circ} \mathrm{C}$, preheating time of $30 \mathrm{~s}$ and load of $2.16 \mathrm{~kg}$.

Thermal stability of the samples was determined in accordance with ASTM E1131. The thermogravimetric analysis (TGA) was performed under nitrogen atmosphere with a heating rate of $20^{\circ} \mathrm{C} / \mathrm{min}$, from 25 to $900{ }^{\circ} \mathrm{C}$ in a TGA Shimadzu model 50 equipment. Differential scanning calorimetry (DSC) was performed according to ASTM D3417 at a heating rate of $10{ }^{\circ} \mathrm{C} / \mathrm{min}$, from 25 to $190^{\circ} \mathrm{C}$, on a TA Instruments Model Q-20 calorimeter. The melting enthalpy of each sample was obtained from the area of its melting peak. Heat of melting of each composite was normalized on the basis of the weight fraction of actual PP present in the sample. The crystallinity index was calculated as the ratio between measured melting enthalpy of the composites and the melting enthalpy of $100 \%$ crystalline PP, taken as $209 \mathrm{~J} / \mathrm{g}^{11}$.

Flexural tests were performed according to ASTM D790 in an Instron model 3382 with $5 \mathrm{kN}$ load-cell, at 2 $\mathrm{mm} / \mathrm{min}$ speed. Tensile testing was performed according to ASTM D638 on the same machine, with a speed of 5 $\mathrm{mm} / \mathrm{min}$ and using an extensometer. Shore D hardness testing followed ASTM D2240, and 20 measurements were taken for each set of samples. Izod impact tests on notched samples were performed according to ASTM D256, with a $2.75 \mathrm{~J}$ pendulum and six samples were used for each set of samples. Morphological analysis of the impact-fractured samples was performed using a Jeol Model Never (JSM) $6510 \mathrm{lv}$ scanning electron microscope at $20 \mathrm{kV}$. All samples were gold-sputtered prior to analysis.

In order to verify the effect of PF and MAPP content variation on the tensile, flexural and impact properties of the composites, single factor ANOVA was used. For PF content, the data was subjected to LSD Fisher Tests in order to compare the average levels of each fiber content.

\section{Results}

\subsection{Physical and Thermal Characteristics}

Density values of the studied samples are shown in Figure 1. As expected, there was an increase in density for a higher amount of $\mathrm{PF}$ due to the higher density of $\mathrm{PF}$ $\left(1.45 \mathrm{~g} / \mathrm{cm}^{3}\right)^{12,13}$ compared to the $\operatorname{PPr}\left(0.93 \mathrm{~g} / \mathrm{cm}^{3}\right)^{14}$. The experimental values were slightly lower than the theoretical values estimated from the rule of mixtures, what may be associated with the presence of a small amount of voids in the samples ${ }^{8}$, or because of variations in the density of the polymer, which is mostly polypropylene, and of the fiber, which was found in the literature.

Figure 2 shows the results of melt flow index for the PPr and the PPr-based composites. According to the literature ${ }^{15,16}$, the higher the amount of fiber embedded in the matrix, the lower the MFI since the presence of fibers hinders the flow and consequently increases viscosity. This trend was also observed in this work when comparing the $80 / 10 / 10$, $70 / 10 / 20$ and $60 / 10 / 30$ samples, or the $100 / 0 / 0$ and $80 / 0 / 20$ samples. In addition, the plasticizing effect (higher MFI) brought by the MAPP is clearly seen, for instance when comparing the $70 / 10 / 20$ and $80 / 0 / 20$ samples, which have the same amount of fibers. 


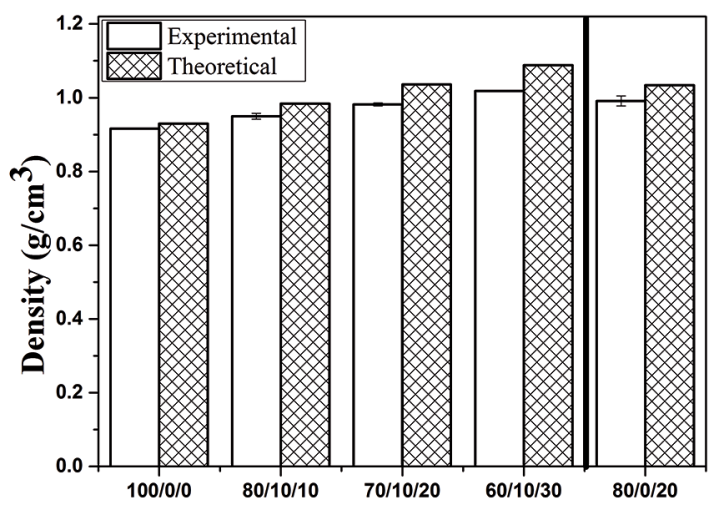

Figure 1: Theoretical and experimental density values for all formulations.

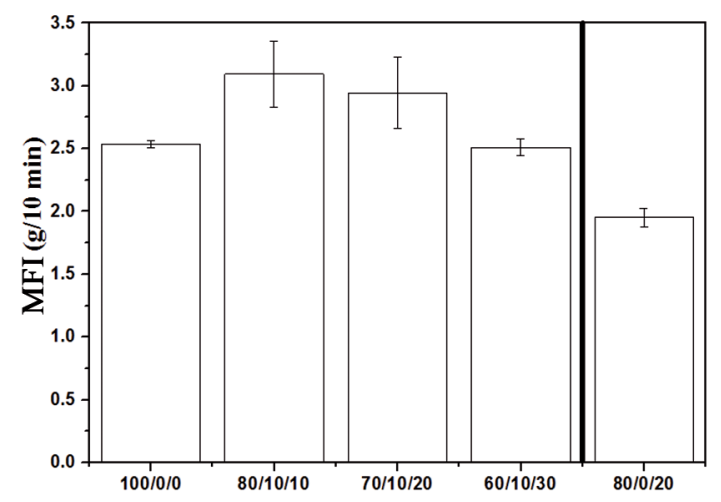

Figure 2: Melt flow index of PPr and PPr-based composites.

The thermal degradation profile of piassava fiber, PPr and their composites, and the respective first derivative curves of weight loss (DTG) are displayed in Figures 3a-b, respectively. Figure 3 a shows that the fiber loses c.a. $8 \%$ of its mass in the $25-150{ }^{\circ} \mathrm{C}$, temperature range due to the loss of volatiles and moisture. The first onset of degradation for $\mathrm{PF}$ is around $260{ }^{\circ} \mathrm{C}{ }^{17}$, much higher than the temperature at which the polymer will be used. Two peaks are observed for piassava fibers in Figure 3b, the first (c.a. $300^{\circ} \mathrm{C}$ ) is related to the degradation of hemicellulose and lignin and the second (c.a. $380^{\circ} \mathrm{C}$ ) to the degradation of cellulose, which is the maximum rate of decomposition of piassava fiber. According to Elzubair ${ }^{18}$, degradation of cellulose is supposed to be faster than lignin, but due to partial crystallinity, cellulose can be more thermally stable than the amorphous components. The $275-425^{\circ} \mathrm{C}$ temperature range is related to the degradation of the constituents of PF, leaving only inorganic material (c.a. $38 \%$ ), similar to the $40 \%$ value reported for piassava by D'Almeida ${ }^{19}$. The overall PF degradation profile follows the same behavior of other vegetable fibers, as described by Satyanarayana ${ }^{20}$.

For pure $\operatorname{PPr}(100 / 0 / 0)$, the range of decomposition occurred in a single step, within $415-480{ }^{\circ} \mathrm{C}$. The curves (a)

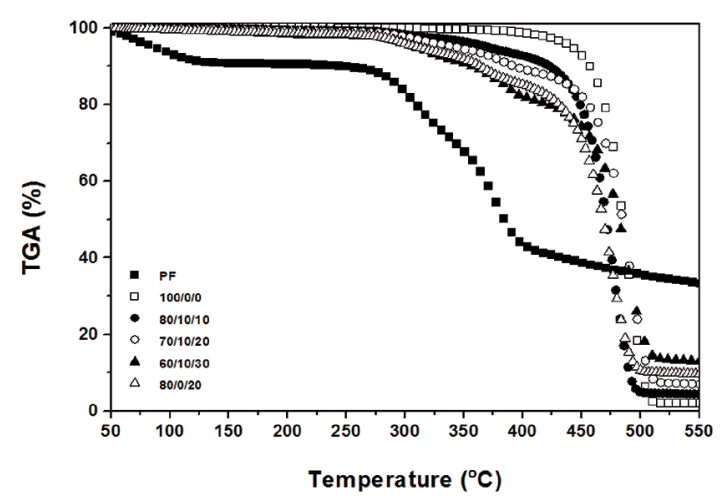

(b)

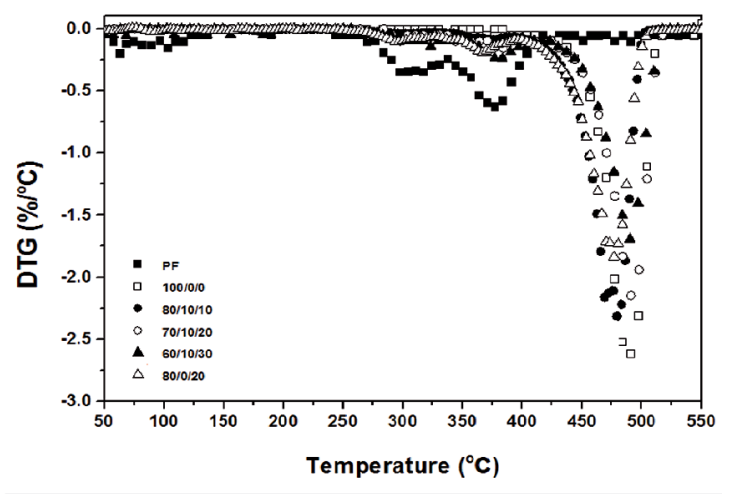

Figure 3: (a) Thermogravimetric analysis curves and (b) Weight loss versus temperature First derivative curves.

obtained for the PPr composites indicate that the addition of $\mathrm{PF}$ reduced the onset temperature of decomposition, and that thermal stability decreased. Also, the composites with higher amount of PF produced more residue. The presence of the coupling agent in the composite has a positive effect, delaying the decomposition of the fiber, probably, because the piassava fiber is better coated with the PP.

Figure 4 shows the cooling and the 2 nd heating curves of PPr and the composites obtained by DSC. The peaks showed a symmetric behavior but with different intensities. In the cooling curve, the first crystallization peak occurred at about $113^{\circ} \mathrm{C}$, probably related to LDPE, commonly used in combination with PP, particularly in mineral water bottle caps which were the main source of PPr used in this study. The second peak, at approximately $125^{\circ} \mathrm{C}$, was identified as the PPr crystallization.

The melting and crystallization temperatures of the analyzed formulations showed no significant variation (see Table 2). The melting enthalpy per unit weight of sample decreased when comparing the PPr and the composites, due to the decrease in the amount of polymer in the mixture. The pure PPr also yielded a higher degree of crystallinity than the mixtures. According to Ota ${ }^{15}$, the increase in fiber 


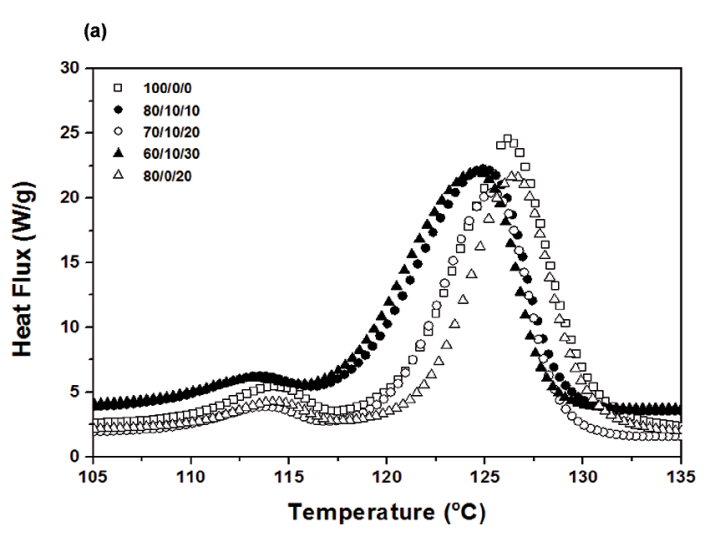

(b)

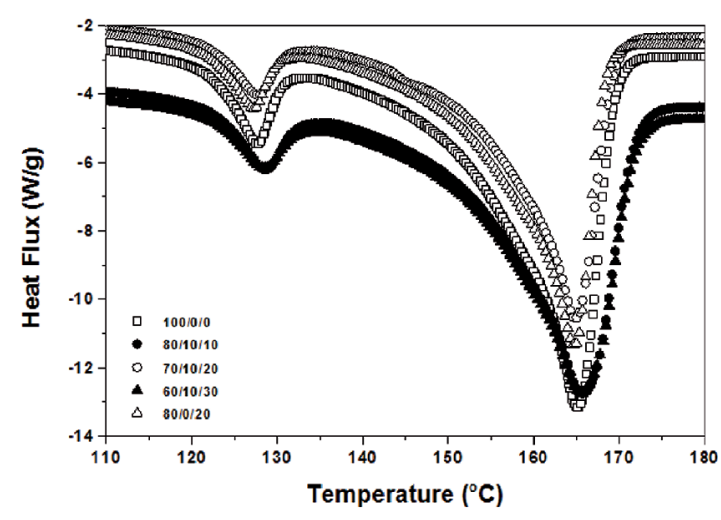

Figure 4: (a) DSC cooling curves and (b) 2nd heating curves.

content may cause steric obstruction during crystallization, reducing the rate of crystallinity of the reinforced material.

Figure 5 shows the heat deflection temperature of all studied formulations. The composites containing higher PF content showed higher HDT, with a more pronounced increase for the $30 \mathrm{wt} \%$ composite. According to Garcia ${ }^{21}$, addition of natural fibers to polymeric matrices increases stiffness of the composite, resulting in higher HDT. For the composite with $30 \% \mathrm{PF}$, the increase of HDT was c.a. 22.5 ${ }^{\circ} \mathrm{C}$ in relation to $\mathrm{PPr}$.

\subsection{Mechanical Characteristics}

The flexural strength and modulus of the various samples are shown in Table 3. Addition of PF led to an increase in strength and the 60/10/30 formulation reached the highest strength and 100/0/0 the lowest, similar to the trend reported for natural fiber reinforced PP/flax by Sahari ${ }^{4}$. Addition of the coupling agent, MAPP, statistically significantly increased strength $(F=39.72 ; p<0.05)$ of the composite due to stronger fiber/matrix adhesion. Prachayawarakorn ${ }^{5}$ and Bettini et al. ${ }^{10}$ also report the same behavior when adding MAPP in the PP/natural fiber composites.

The sample with $10 \mathrm{wt} \%$ of fiber reached low strength (33.7 MPa) because of non-uniformity in the distribution of the fibers due to its low concentration in the polymer matrix. There was also a statistically significant increase in modulus $(\mathrm{F}=25.69 ; \mathrm{p}<0.05)$ as the concentration of $\mathrm{PF}$ increased, as expected.

Figure 6 shows median stress $v s$ strain curves and the modulus values obtained for the samples. The pure PPr sample showed much higher ductility than the composites containing PF and the strain of the material decreased as the concentration of PF increased, indicating a more brittle material. Tensile strength increased, but was not statistically significant, for higher PF content $(F=1.44$; $\mathrm{p}>0.05$ ), and the compound with $30 \mathrm{wt} \% \mathrm{PF}$ reached highest strength (26 MPa). Similar values of tensile strength and modulus were reported by Elzubair ${ }^{18}$ in the research of polyethylene/piassava fiber composites. The increase in stiffness and strength of composites produced with discontinuous fibers in a thermoplastic matrix was also reported by Antich ${ }^{22}$.

However, in the 80/0/20 formulation, the presence of PF statistically significantly reduced tensile strength $(\mathrm{F}=382.53$; $\mathrm{p}<0.05)$ compared with the pure polymer. This can be explained by the poor interfacial adhesion between PF and the PPr matrix. Even then, elastic modulus increased, but was not statistically significant $(\mathrm{F}=0.71 ; \mathrm{p}>0.05)$, due to the reduced mobility of the polymeric matrix brought by the incorporation of PF. Without the compatibilizer, adhesion between the phases was poor, and the fiber acted as discontinuities in the matrix, behaving as stress concentrators, weakening the composite. When load is applied to the material, it is not properly transferred to the fibers and they may be easily pulled out of the matrix ${ }^{10}$.

Figure 7 shows Shore D hardness results and it can be clearly observed an increase in hardness as the concentration of PF increased, e.g. 62 Shore D for pure PPr and 70 Shore $\mathrm{D}$ for the formulation with $30 \mathrm{wt} \% \mathrm{PF}$. This was consistent with the increase in stiffness of the composite.

Table 2: Thermal properties of the analyzed formulations.

\begin{tabular}{lccccc}
\hline Samples & $\begin{array}{c}\text { Crystallization } \\
\text { temperature }\left({ }^{\circ} \mathrm{C}\right)\end{array}$ & $\begin{array}{c}\text { Enthalpy of } \\
\text { crystallization }(\mathrm{J} / \mathrm{g})\end{array}$ & $\begin{array}{c}\text { Melting } \\
\text { temperature }\left({ }^{\circ} \mathrm{C}\right)\end{array}$ & $\begin{array}{c}\text { Enthalpy of melting } \\
(\mathrm{J} / \mathrm{g})\end{array}$ & $\begin{array}{c}\text { Crystallinity index } \\
(\%)\end{array}$ \\
\hline $100 / 0 / 0$ & 126.0 & 73.3 & 165.1 & 71.5 & 34.2 \\
$80 / 10 / 10$ & 125.0 & 59.67 & 165.8 & 59.4 & 31.5 \\
$70 / 10 / 20$ & 125.5 & 47.44 & 164.7 & 46.08 & 27.5 \\
$60 / 10 / 30$ & 124.5 & 54.95 & 165.5 & 44.17 & 30.2 \\
$80 / 0 / 20$ & 126.5 & 47.36 & 164.7 & 45.68 & 27.3 \\
\hline
\end{tabular}




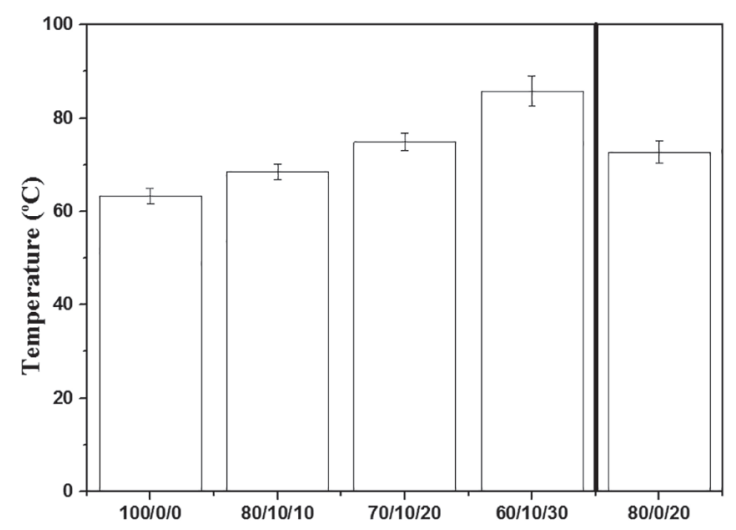

Figure 5: HDT obtained for the studied formulations.

Table 3: Flexural strength and Flexural modulus of the formulations

\begin{tabular}{lcc}
\hline Samples & Flexural strength $(\mathrm{MPa})$ & Flexural modulus $(\mathrm{MPa})$ \\
\hline $100 / 0 / 0$ & $32.8^{\mathrm{a}}$ & $1004^{\mathrm{a}}$ \\
$80 / 10 / 10$ & $33.7^{\mathrm{b}}$ & $980^{\mathrm{a}}$ \\
$70 / 10 / 20$ & $41.7^{\mathrm{c}}$ & $1298^{\mathrm{b}}$ \\
$60 / 10 / 30$ & $45.0^{\mathrm{d}}$ & $1511^{\mathrm{c}}$ \\
$80 / 0 / 20$ & 37.8 & 1355 \\
\hline
\end{tabular}

ANOVA analysis

(a)

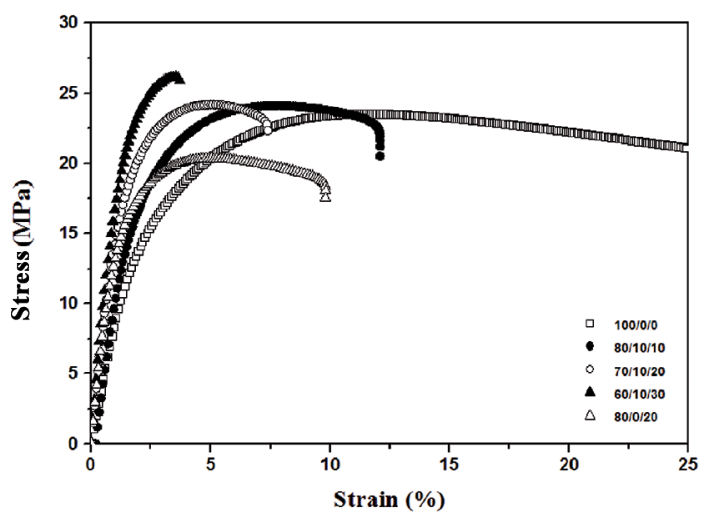

(b)

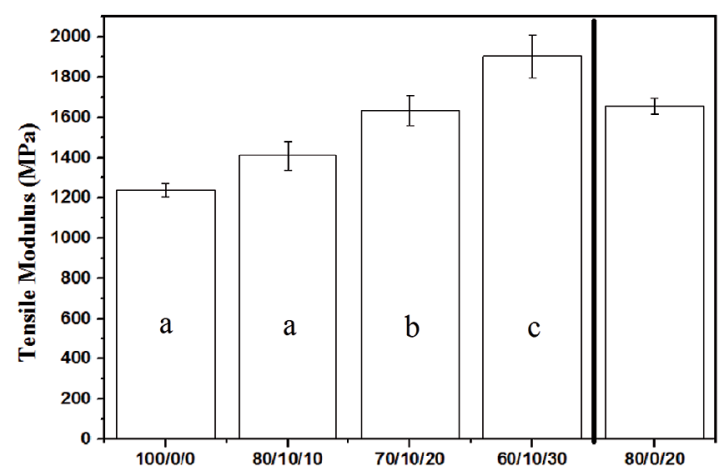

Figure 6: (a) Tensile stress-strain curve and (b) Tensile modulus of the samples.

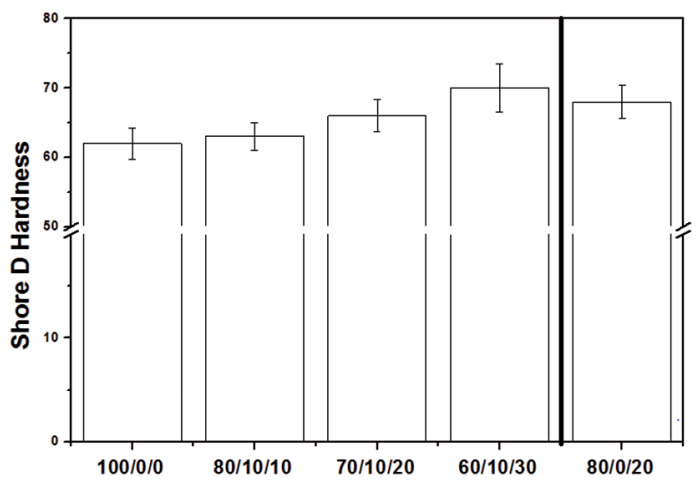

Figure 7: Shore D hardness testing results.

In the impact testing, full break was obtained in all cases and Figure 8 shows the resulting mean impact strength values. The increase in the amount of PF resulted in a statistically significantly decrease in strength $(F=16.86 ; p<0.05)$. The polymeric matrix exhibited the highest impact energy absorption $\left(10.5 \mathrm{~kJ} / \mathrm{m}^{2}\right)$ and the sample with $30 \mathrm{wt} \% \mathrm{PF}$ the smallest $\left(7.1 \mathrm{~kJ} / \mathrm{m}^{2}\right)$, similar to the composition without MAPP. According to Farouk ${ }^{23}$, the greater the amount of fibers incorporated in the ductile PP matrix, the more rigid becomes the material and the lower its ability to absorb energy in an impact event.

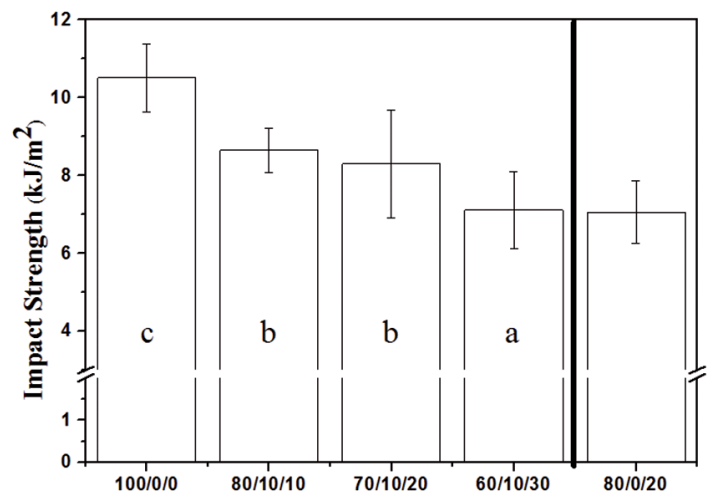

Figure 8: Impact strength of the formulations.

Figure 9 shows the surface of the samples subjected to impact testing, as examined by SEM. The 80/10/10 formulation, Figure 9a-b, appears to show piassava fibers more firmly adhered to the matrix, with little displacement and fiber fracture close to the plane of the matrix. For the $70 / 10 / 20$ composition (Figure 9c-d), one can notice the presence of voids due to the pullout of some fibers, however, most of the PF remained adhered to the matrix. In comparison to the formulation without MAPP (Figure $9 \mathrm{~g}-\mathrm{h}$ ), one can observe that the fiber is not wetted by the matrix, indicating efficiency of the coupling agent. 


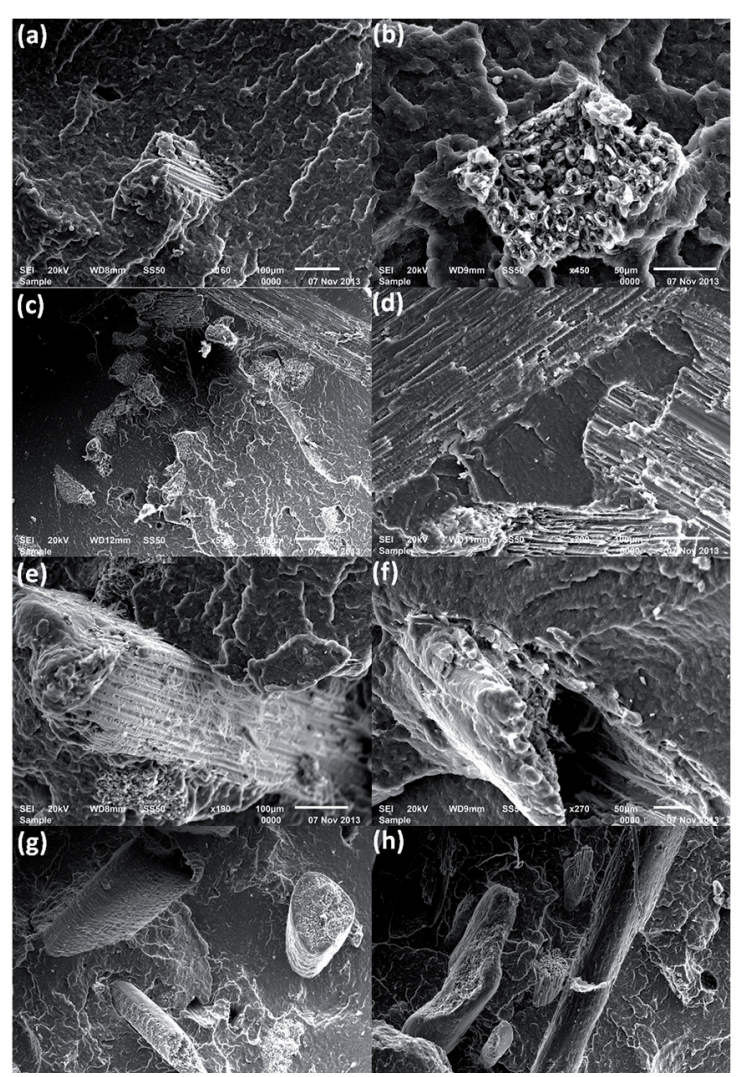

Figure 9: Micrograph of the impact-fractured samples: 80/10/10 $((\mathrm{a}, \mathrm{b})-\times 160, \times 450), 70 / 10 / 20((\mathrm{c}, \mathrm{d})-\times 55, \times 200), 60 / 10 / 30((\mathrm{e}$, f) $-\times 190, \times 270)$, and $80 / 0 / 20((\mathrm{~g}, \mathrm{~h})-\times 75, \times 80)$ composites.

All samples with $10 \mathrm{wt} \%$ of MAPP exhibited similar fracture surfaces. In Figs. $9 \mathrm{~g}$-h, the fracture surface of the $80 / 0 / 20$ compound revealed the existence of empty spaces (fibers pullout during the breakdown of the sample), which demonstrates poor interaction between the nonpolar matrix and the polar PF, thus justifying the decrease in tensile properties observed for these composites and the need for the coupling agent.

\section{Conclusions}

- All compositions with piassava (10,20 and $30 \mathrm{wt} \%)$ yielded superior tensile and flexural properties compared to the pure PPr when $10 \mathrm{wt} \%$ of MAPP was used.

- The Izod impact strength decreased with fiber incorporation, what is expected for natural fibers, whereas hardness and heat deflection temperature of these composites increased.

- The morphological analysis helped the evaluation of the efficiency of the coupling agent because the fibers were more adhered to the matrix when MAPP was used. The composite also displayed a clear trend of lower thermal stability with the addition of fiber. MAPP also delayed the decomposition of the fiber in the composites.

- Addition of PF showed some influence on the degree of crystallinity and the crystallization temperature of PPr. And the presence of two peaks in the DSC analysis indicated contamination of PP with polyethylene, which is justified considering the post-consumer source of the polypropylene used in this study, which was recovered from discarded plastic items.

- In all, it was concluded that the performance of piassava fibers as reinforcement in a PPr matrix was satisfactory, resulting in good mechanical properties and proving their potential use in WPC.

\section{Acknowledgements}

The authors thank SENAI-CIMATEC (polymer laboratory) for their help with the analyses.

\section{References}

1. Baghaei B, Skrifvars M, Berglin L. Characterization of thermoplastic natural fibre composites made from woven hybrid yarn prepregs with different weave pattern. Composites Part A: Applied Science and Manufacturing. 2015;76:154-161.

2. Ku H, Wang H, Pattarachaiyakoop N, Trada M. A review on the tensile properties of natural fiber reinforced polymer composites. Composites Part B: Engineering. 2011;42(4):856-873.

3. Gironès J, López JP, Mutjé P, Carvalho AJF, Curvelo AAS, Vilaseca F. Natural fiber-reinforced thermoplastic starch composites obtained by melt processing. Composites Science and Technology. 2012;72(7):858-863.

4. Sahari J, Sapuan SM. Natural Fibre Reinforced Biodegradable Polymer Composites. Advanced Materials Reviews. 2011;30(2):166-174.

5. Catto AL, Stefani BV, Ribeiro VF, Santana RMC. Influence of coupling agent in compatibility of post-consumer HDPE in thermoplastic composites reinforced with eucalyptus fiber. Materials Research. 2014;17(suppl.1):203-209.

6. Jeske H, Schirp A, Cornelius F. Development of a thermogravimetric analysis (TGA) method for quantitative analysis of wood flour and polypropylene in wood plastic composites (WPC). Thermochimica Acta. 2012;543:165-171.

7. Behzad HM, Ashori A, Tarmian A, Tajvidi M. Impacts of wood preservative treatments on some physico-mechanical properties of wood flour/high density polyethylene composites. Construction and Building Materials. 2012;35:246-250.

8. Połeć I, Hine PJ, Bonner MJ, Ward IM, Barton DC. Die drawn wood polymer composites. I. Mechanical properties. Composites Science and Technology. 2010;70(1):45-52.

9. Rosa SML, Santos EF, Ferreira CA, Nachtigall SMB. Studies on the properties of rice-husk-filled-PP composites - effect of maleated PP. Materials Research. 2009;12(3):333-338. 
10. Bettini SHP, Antunes MC, Magnabosco R. Investigation on the effect of a compatibilizer on the fatigue behavior of $\mathrm{PP} /$ coir fiber composites. Polymer Engineering \& Science. 2011;52(11):2184-2190.

11. Nuñez AJ, Kenny JM, Reboredo MM, Aranguren MI, Marcovich NE. Thermal and dynamic mechanical characterization of polypropylene-woodflour composites. Polymer Engineering \& Science. 2002;42(4):733-742.

12. Aquino RCMP, D'almeida JRM, Monteiro SN. Flexural mechanical properties of piassava fibers (Attalea funifera)-resin matrix composites. Journal of Materials Science Letters. 2001;20(11):1017-1019.

13. Nascimento DCO, Ferreira AS, Monteiro SN, Aquino RCMP, Satyanarayana KG. Studies on the characterization of piassava fibers and their epoxy composites. Composites Part A: Applied Science and Manufacturing. 2011;43(3):353-362.

14. Wang W, Sain M, Cooper PA. Hygrothermal weathering of rice hull/HDPE composites under extreme climatic conditions. Polymer Degradation and Stability. 2005;90(3):540-545.

15. Ota WN, Amico SC, Satyanarayana KG. Studies on the combined effect of injection temperature and fiber content on the properties of polypropylene-glass fiber composites. Composites Science and Technology. 2005;65:873-881.

16. Pigatto C, Almeida Júnior JHS, Ornaghi Júnior HL, Rodríguez AL, Mählmann CM, Amico SC. Study of polypropylene/ ethylene-propylene-diene monomer blends reinforced with sisal fibers. Polymer Composites. 2012;33(12):2262-2270.
17. Avelar FF, Bianchi ML, Gonçalves M, Mota EG. The use of piassava fibers (Attalea funifera) in the preparation of activated carbon. Bioresource Technology. 2012;101(12):4639-4645.

18. Elzubair A, Suarez JCM. Mechanical behavior of recycled polyethylene/piassava fiber composites. Materials Science and Engineering: A. 2012;557:29-35.

19. d'Almeida JRM, Aquino RCMP, Monteiro SN. Tensile mechanical properties, morphological aspects and chemical characterization of piassava (Attalea Funifera) fibers. Composites Part A: Applied Science and Manufacturing. 2006;37(9):1473-1479.

20. Satyanarayana KG, Guimarães JL, Wypych F. Studies on lignocellulosic fibers of Brazil. Part I: Source, production, morphology, properties and applications. Composites Part A: Applied Science and Manufacturing. 2007;38(7):1564-1709.

21. García M, Garmendia I, García J. Influence of natural fiber type in eco-composites. Journal of Applied Polymer Science. 2008;107(5):2994-3004.

22. Antich P, Vázquez A, Mondragon I, Bernal C. Mechanical behavior of high impact polystyrene reinforced with short sisal fibers. Composites Part A: Applied Science and Manufacturing. 2006;37(1):139-150.

23. Faruk O, Bledzki AK, Fink HP, Sain M. Biocomposites reinforced with natural fibers: 2000-2010. Progress in Polymer Science. 2012;37(11):1552-1596. 